\title{
FEV6 as a surrogate for FVC in detecting airways obstruction and restriction in the workplace
}

\author{
M. Akpinar-Elci*, K.B. Fedan* and P.L. Enright ${ }^{\#}$
}

ABSTRACT: Compared with measurements of forced vital capacity (FVC), using the forced expiratory volume in six seconds (FEV6) reduces test time and frustration. It was hypothesised that using FEV6 in the workplace setting would result in an acceptably low misclassification rate for detecting airways obstruction and spirometry-defined restriction when compared with using the traditional FVC.

Experienced technicians from the National Institute for Occupational Safety and Health performed spirometry using dry rolling-seal spirometers as per American Thoracic Society guidelines in four workplace investigations. Airways obstruction was defined as an FEV $1 / F^{2}$ \% below the lower limit of normal (LLN) using National Health and Nutrition Examination Survey III reference equations. Restriction was defined as an FVC below the LLN with a normal FEV $1 / F V C \%$. These "gold standard" definitions were compared with definitions based on FEV6 (obstruction: $F_{1} V_{1 / F E V} 6$ below the LLN; restriction: FEV 6 below the LLN with a normal FEV1/FEV6).

The median (range) age of the 1,139 workers was 37 yrs (18-71 yrs) and $51.4 \%$ were male. A significantly high overall agreement was obtained between the two definitions.

In conclusion, the current results confirm that forced expiratory volume in six seconds can be used as a surrogate for forced vital capacity in detecting airways obstruction and restriction in workers, although with some misclassification when compared to obtaining American Thoracic Society-acceptable manoeuvres of longer duration.

KEYWORDS: Forced expiratory volume in six seconds, pulmonary function test, spirometry

$\mathbf{T}$ he most widely used pulmonary function test is spirometry. However, spirometry is an effort-dependent test that requires careful instruction and the full cooperation of the test subject. The inability to perform acceptable and repeatable manoeuvres may be due to poor subject motivation, poor coaching techniques or failure to understand instructions [1]. A prolonged exhalation effort is often needed to obtain a volume-time plateau to meet acceptable end-oftest (EOT) criteria. In subjects with airways obstruction, an acceptable EOT plateau may not occur even after $20 \mathrm{~s}$ of exhalation [2,3]. This can be physically exhausting and frustrating for both the subject and the technician, and occasionally results in subject syncope.

The results of spirometry tests are critically important in the occupational setting when used for screening and surveillance programmes [4].

For Editorial comments see page 245.
Poor quality tests increase the misclassification rates for restriction and airways obstruction. The use of forced expiratory volume in six seconds (FEV6) as a surrogate for the forced vital capacity (FVC) has recently been found to be acceptable in clinical settings $[5,6]$. Spirometry results from four recently performed investigations were used to evaluate the possibility that use of FEV6 would also be acceptable in workplace investigations.

\section{METHODS}

\section{Study population}

Spirometry results were collected from 1,143 workers from four different workplace investigations during 2000-2003. All workers signed consent forms approved by the National Institute for Occupational Safety and Health (NIOSH) Human Studies Review Board (Morgantown, WV, USA).

\section{Spirometry}

Spirometry was performed with automated Ohio 827 dry rolling-seal spirometers (Ohio Medical

\section{AFFILIATIONS}

${ }^{*}$ Centers for Disease Control and Prevention (CDC)/National Institute for Occupational Safety and Health (NIOSH), Division of Respiratory Disease Studies, Morgantown, WV, and

\#The Respiratory Science Center, College of Medicine, The University of Arizona, Tucson, AZ, USA.

CORRESPONDENCE

M. Akpinar-Elci

NIOSH Division of Respiratory

Diseases Studies

Field Studies Branch

Mail Stop $\mathrm{H}-2800$

1095 Willowdale Rd

Morgantown

WV 26505

USA

Fax: 13042855820

E-mail: melci@cdc.gov

Received:

July 122005

Accepted after revision:

September 082005 
Products, Madison, WI, USA) with software that checks for unacceptable manoeuvres [7]. Four highly experienced NIOSH technicians followed American Thoracic Society (ATS) spirometry recommendations [1]. The test results were compared to the lower limit of normal (LLN) values from the National Health and Examination Survey (NHANES) III reference values [8] to identify workers with two abnormal spirometry patterns: obstruction and low vital capacity [9]. Airways obstruction was defined as FEV1/FVC \% below the LLN. Spirometry-defined "restriction" was a FVC below the LLN with a normal FEV1/FVC \%. The "traditional" definitions were compared with definitions based on FEV6 (obstruction: FEV1/FEV6 below the LLN based on FEV6 from NHANES III; restriction: FEV6 below the LLN and normal FEV1/FEV6).

\section{Statistical analyses}

The current authors calculated the sensitivity, specificity, and positive and negative predictive values of using the FEV6 for the determination of overall abnormal spirometry, airways obstruction and restriction. The agreement between test result classification based on FVC and FEV6 was also calculated using the Kappa test.

Those individuals classified differently by two techniques were evaluated separately. Their age, height and pack-yrs data were compared with rest of the group by paired t-test. Everand never-smoking status and test reproducibility were tested using Chi-squared tests.

\section{RESULTS}

Only four out of the 1,143 workers had invalid spirometry results (test sessions where less than three acceptable manoeuvres were obtained), so their results were excluded from this analysis. The median (range) age of the remaining 1,139 workers was 37 yrs (18-71 yrs) and 51.4\% were male (table 1). Among them, $42.0 \%$ were current smokers, $15.4 \%$ were former smokers and $42.6 \%$ were never-smokers.

Interpretations based on the FEV6 had a high agreement rate with those based on the FVC (Kappa $=0.90 ; \mathrm{p}<0.001$; table 2). When the values of FEV1/FEV6 \% were used, the sensitivity for detecting airways obstruction was $92 \%$ and specificity $98 \%$. For detecting restriction, the sensitivity was $89 \%$ and specificity was $99 \%$. For abnormal spirometry, the sensitivity was $94 \%$ and specificity was $98 \%$. Positive and negative predictive values for abnormal spirometry were $92 \%$ and $98 \%$, respectively.

\begin{tabular}{lccccc} 
TABLE 1 & $\begin{array}{l}\text { Demographic characteristics of workers at the } \\
\text { four plants studied }\end{array}$ \\
& $\begin{array}{c}\text { Workers } \\
\mathbf{n}\end{array}$ & $\begin{array}{c}\text { Caucasian } \\
\%\end{array}$ & $\begin{array}{c}\text { Male } \\
\%\end{array}$ & $\begin{array}{c}\text { Ever-smoking } \\
\%\end{array}$ & Age yrs \\
\hline Workplace A & 160 & 80.6 & 58 & 53.8 & $43.5 \pm 11.6$ \\
Workplace B & 215 & 95.4 & 68 & 72.6 & $35.8 \pm 9.4$ \\
Workplace C & 236 & 74.2 & 39 & 37.0 & $46.4 \pm 8.3$ \\
Workplace D & 528 & 83.3 & 48 & 61.4 & $32.8 \pm 11.6$ \\
\hline
\end{tabular}

Data are presented as mean $\pm \mathrm{SD}$, unless otherwise stated.

\begin{tabular}{lcccc} 
TABLE 2 & $\begin{array}{l}\text { Comparisons of spirometry classifications using } \\
\text { the two techniques }\end{array}$ & Total \\
& \multicolumn{3}{c}{ Based on FVC } & \\
\cline { 2 - 4 } & Normal & Obstruction & Restriction & \\
& \multicolumn{4}{c}{} \\
Based on FEV6 & 862 & 8 & 8 & 878 \\
$\quad$ Normal & 14 & 152 & 2 & 168 \\
$\quad$ Obstruction & 6 & 5 & 82 & 93 \\
$\quad$ Restriction & 882 & 165 & 92 & 1139 \\
Total & & &
\end{tabular}

Data are presented as n. FVC: forced vital capacity; FEV6: forced expiratory volume in six seconds.

The spirometry test results for 43 workers $(3.8 \%)$ were classified differently by the two techniques, and all of them had observed values close to the LLNs. These inconsistently classified cases are found in the upper left and lower right quadrants of figure 1 . Among these 43 workers, pack-yrs of cigarette use were significantly higher $(p=0.009)$ than in rest of the group. Age, sex, race, test reproducibility, heights and ever-smoking did not differ between these two groups.

\section{DISCUSSION}

Clinical practice guidelines state that airways obstruction is defined as a low FEV1/FVC [1,9]. Errors in the measurement of either the FEV1 or the FVC will cause errors in the measurement of this ratio, which may cause misclassification of the results during the interpretation process, especially if the results are near the LLN range. Workers participating in a workplace screening or surveillance programme are generally healthy, but some are at risk for developing lung disease from their workplace exposures, so the median spirometry values are often closer to the LLN than in groups of patients with respiratory symptoms being referred to a pulmonary function laboratory for testing.

In order to avoid errors in the measurement of the FVC, the 1994 ATS recommendation stated that, to be considered acceptable, each manoeuvre should last until a plateau is achieved on the volume-time graph [1]. This EOT criterion is defined as a $<20-\mathrm{mL}$ change in volume during the final $2 \mathrm{~s}$ of the manoeuvre. Patients with airways obstruction frequently fail to meet this EOT criterion [3], but, when coached to perform a "relaxed expiration", they are somewhat more successful [10]. However, spirometry reference equations were obtained from studies where the subjects were coached to perform with maximal exhalation efforts, so relaxed expirations cannot be recommended as a solution to this problem [11].

The current authors understand that a normal FVC rules out restriction [12], and that a low FVC poorly predicts a low total lung capacity (TLC; true restriction), requiring confirmation by static lung volume tests, which include the TLC, the residual volume and the functional residual capacity [9]; however, static lung volume tests are rarely performed in occupational settings. Failure to obtain FVC manoeuvres with acceptable EOT plateaus is relatively common in the occupational and primary care settings, in some cases due to time constraints, 

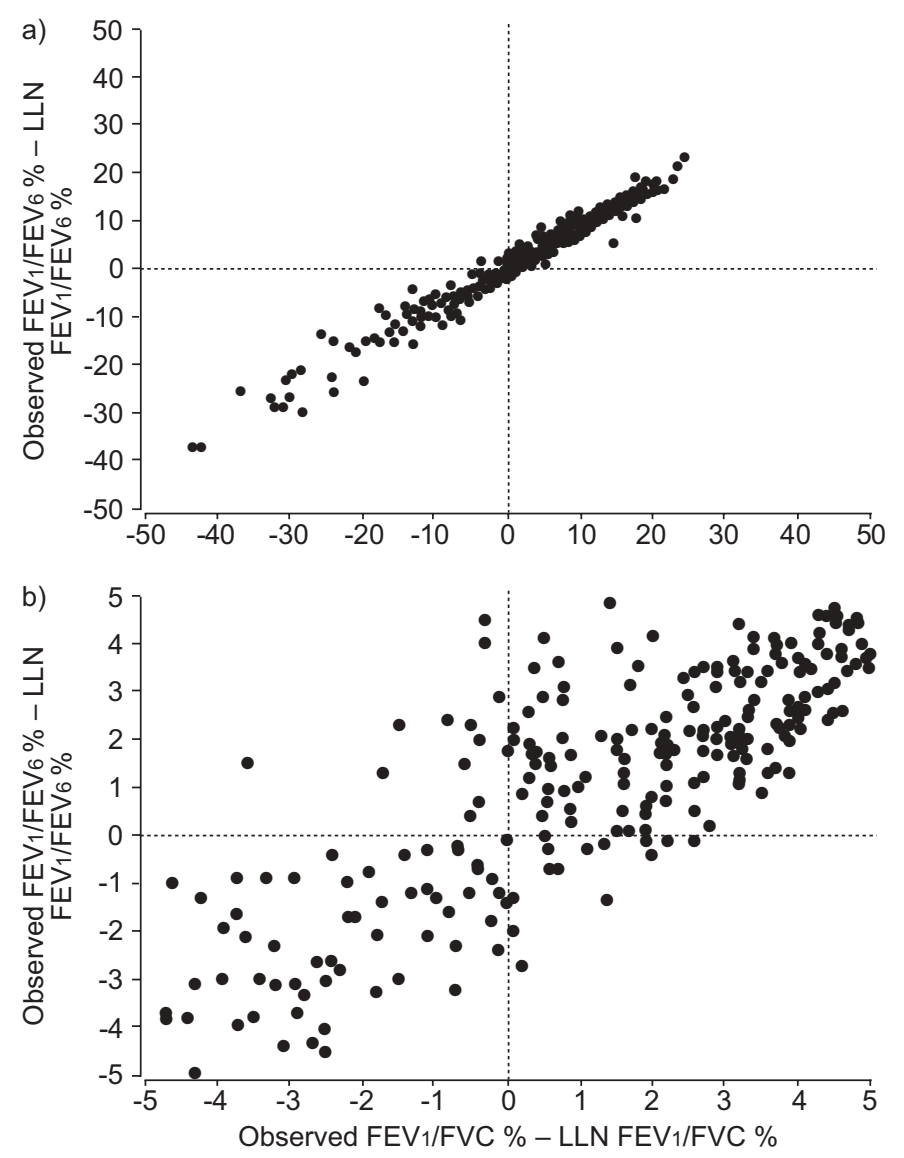

FIGURE 1. a) Overall plot of difference between observed measures and the lower limit of normal (LLN) for both airways obstruction definitions. b) Detailed view of a) in the region of $\pm 5 \%$ difference. Quadrant I (upper left): classified as not obstructive by forced expiratory volume in one second (FEV 1 )/FEV 6 and obstruction by FEV1/forced vital capacity (FVC) (1.1\%); quadrant II (upper right): classified as not obstructive by FEV $1 / F E V_{6}$ and not obstructive by FEV1/FVC (84.1\%); quadrant III (lower left): classified as obstructive by FEV1/FEV6 and obstruction by $\mathrm{FEV}_{1} / \mathrm{FVC}$ (13.4\%); quadrant IV (lower right): classified as obstruction by FEV1/FEV6 and not obstructive by $\mathrm{FEV}_{1} / \mathrm{FVC}(1.4 \%)$.

lack of adequate technician training or dedication (leading to poor coaching), poor motivation of the subjects to keep blowing out, a high prevalence of subjects with severe airway obstruction, or a faulty spirometer that prematurely terminates data collection. These short FVC manoeuvres cause underestimations of the true FVC, making a healthy subject's FVC more likely to fall below the LLN, a falsely positive result mimicking 'restriction.' At the same time, the FEV1/FVC ratio is falsely increased, so that subjects with mild airways obstruction are more likely to have a falsely negative result. These short exhalation times should be detected either by the quality control software of modern spirometers or by the physician interpreting the results. Performance of slow vital capacity (SVC) manoeuvres may demonstrate a vital capacity in the normal range, thereby ruling out restriction, but SVC manoeuvres are rarely performed outside of hospital-based pulmonary function laboratories.

Unfortunately, many spirometers that are currently in use either lack manoeuvre quality-control checks and messages, or they are turned off or ignored. Physicians interpreting the spirometry tests may miss the short exhalation times, the lack of EOT plateaus, or may view only the numeric results. Both types of misclassification of spirometry interpretations have negative consequences in the workplace setting. A potential method for reducing this misclassification rate in the "realworld" (nonresearch) setting, where short manoeuvres are common, is to utilise reference equations based on 6-s manoeuvres.

GLINDMEYER et al. [13] noted that short FVC manoeuvres result in underestimates of the FVC, and considered recommending shorter spirometry manoeuvres (allowing subjects to stop after 5,6 or $7 \mathrm{~s}$ ). However, the ability to use shorter manoeuvres without high misclassification rates awaited the publication of reference equations for these variables from shorter manoeuvres. More than a decade later, the NHANES III study finally provided reference equations for the FEV6 and FEV1/ FEV6 [8]. The National Lung Health Education Program quickly recommended that 6-s spirometry manoeuvres and the NHANES III reference equations should be used for detecting airways obstruction in adult cigarette smokers being seen by general practitioners who provide primary care [14]. Some new models of office spirometers provide NHANES III reference equations for the FEV6 and FEV1/FEV6, and base their automated interpretations on these values.

SWANNEY et al. [6] showed that using the FEV1/FEV6 to detect airways obstruction in 337 patients referred to a hospital-based pulmonary function laboratory in New Zealand resulted in a low misclassification rate when compared with the traditional FEV1/FVC. ENRIGHT et al. [5] then showed that the FEV1/FEV6 predicted the subsequent 5-yr decline in FEV1, as well as the FEV1/FVC in 5,887 adult smokers.

There is currently some minor confusion regarding the nomenclature for measurements of the vital capacity from 6-s spirometry manoeuvres. The 1999 NHANES III study defined the FEV 6 as the volume in the spirometer at exactly $6 \mathrm{~s}$ after the manoeuvre had begun (using the standard back-extrapolation technique to define the start of the exhalation manoeuvre). The air collected inside volume spirometers, such as the ones used by the NHANES III study, cools throughout the FVC manoeuvre (especially when the ambient temperature is relatively low); therefore, in some healthy young subjects who rapidly exhale almost all of their air within $6 \mathrm{~s}$, the cooling and contraction of exhaled air in the spirometer causes the volume-time graph to "droop" before the 6-s mark. Such slight downward slopes of the volume-time tracing mimic the effect caused by a leak in the spirometer, and make the FEV6 slightly lower than the largest volume obtained at any time during the first $6 \mathrm{~s}$ (recently defined as the FVC6). Fastresponding temperature sensors inside the volume spirometer (with real-time body temperature, ambient pressure, saturated with water vapour corrections) can eliminate this artefact, but this degree of sophistication is not currently available in any commercial volume spirometers (and is not used in NIOSH field studies). A re-analysis of the raw data from the NHANES III study recently provided reference equations for the newly defined FVC6 and FEV1/FVC6 [15]. However, the mean differences in the FEV6 and FVC6 are very small $(<0.05 \mathrm{~L})$ and do not occur when flow-sensing spirometers are utilised. 
A recent study from Spain provides an alternate set of FEV6 and FEV1/FEV6 reference equations for older adults [16].

The current results confirm that the forced expiratory volume in six seconds can be used as a surrogate for forced vital capacity in detecting airways obstruction and restriction in workers, although with some misclassification when compared with obtaining American Thoracic Society-acceptable manoeuvres of longer duration. Additional studies are recommended to determine if the current results are generalisable for those using flow-sensing spirometers in occupational settings.

\section{ACKNOWLEDGEMENTS}

The authors would like to thank O.C. Elci, B. Tift, D. Freeland, J. Taylor, D. Spainhour, M. Pflock and R. Petsko for their help. It should be noted that the findings and conclusions in this report are those of the authors and do not necessarily represent the views of the National Institute for Occupational Safety and Health.

\section{REFERENCES}

1 Standardization of Spirometry, 1994 Update. American Thoracic Society. Am J Respir Crit Care Med 1995; 152: 1107-1136.

2 Kelley A, Garshick E, Gross ER, Lieberman SL, Tun CG, Brown R. Spirometry testing standards in spinal cord injury. Chest 2003; 123: 725-730.

3 Stoller JK, Buist AS, Burrows B, et al. Quality control of spirometry testing in the registry for patients with severe alpha1-antitrypsin deficiency. alpha1-Antitrypsin Deficiency Registry Study Group. Chest 1997; 111: 899-909.

4 Townsend MC. ACOEM position statement. Spirometry in the occupational setting. American College of Occupational and Environmental Medicine. J Occup Environ Med 2000; 42: 228-245.

5 Enright RL, Connett JE, Bailey WC. The FEV1/FEV6 predicts lung function decline in adult smokers. Respir Med 2002; 96: 444-449.
6 Swanney MP, Jensen RL, Crichton DA, Beckert LE, Cardno LA, Crapo RO. FEV(6) is an acceptable surrogate for FVC in the spirometric diagnosis of airway obstruction and restriction. Am J Respir Crit Care Med 2000; 162: 917-919.

7 Banks DE, Wang ML, McCabe L, Billie M, Hankinson J. Improvement in lung function measurements using a flow spirometer that emphasizes computer assessment of test quality. J Occup Environ Med 1996; 38: 279-283.

8 Hankinson JL, Odencrantz JR, Fedan KB. Spirometric reference values from a sample of the general U.S population. Am J Respir Crit Care Med 1999; 159: 179-187.

9 Lung function testing: selection of reference values and interpretative strategies. American Thoracic Society. Am Rev Respir Dis 1991; 144: 1202-1218.

10 Stoller JK, Basheda S, Laskowski D, Goormastic M, McCarthy K. Trial of standard versus modified expiration to achieve end-of-test spirometry criteria. Am Rev Respir Dis 1993; 148: 275-280.

11 Enright P. Can we relax during spirometry? Am Rev Respir Dis 1993; 148: 274.

12 Aaron SD, Dales RE, Cardinal P. How accurate is spirometry at predicting restrictive pulmonary impairment? Chest 1999; 115: 869-873.

13 Glindmeyer HW, Jones RN, Barkman HW, et al. Spirometry: quantitative test criteria and test acceptability. Am Rev Respir Dis 1987; 136: 449-452.

14 Ferguson GT, Enright PL, Buist AS, et al. Office spirometry for lung health assessment in adults: a consensus statement from the National Lung Health Education Program. Chest 2000; 117: 1146-1161.

15 Hankinson JL, Crapo RO, Jensen RL. Spirometric reference values for the 6-s FVC maneuver. Chest 2003; 124: 1805-1811.

16 Garcia-Rio F, Pino JM, Dorgham A, Alonso A, Villamore J. Spirometric reference equations for European females and males aged 65-85 yrs. Eur Respir J 2004; 24: 397-405. 